\title{
A Comparative Study on Induced Currents in Steel Reinforced Building Due to a Nearby Lightning Strike to Ground and a Strike to Nearby Elevated Object
}

\author{
Vishwanath Hegde $^{1, *}$, Vinoda shivanand ${ }^{2}$ \\ ${ }^{1}$ Electrical and Electronics Engineering, M.C.E Hassan, Karnataka, India \\ ${ }^{2}$ Electrical and Electronics Engineering, K.L.E.I.T, Hubli, India \\ *Corresponding author: hedge_mce@rediffmail.com
}

Received November 17, 2013; Revised December 14, 2013; Accepted January 03, 2014

\begin{abstract}
In the present work a study is carried out to determine the magnitude and nature of the induced current in the steel of a steel reinforced concrete building due to a nearby lightning stroke to ground and strike to nearby elevated objects. A comparison of the two is presented. For the study, buildings of three different heights with number of floors are considered. The vertical down conductor of different heights is considered as nearby elevated object. Lightning channel of length $1 \mathrm{~km}$ is employed. Two velocities of propagation of channel current, one equal to velocity of light and another of $1 / 3$ of velocity of light are considered. A current source model for the source is employed for the study. Electromagnetic model is employed and Numerical Electromagnetic Code-2 (NEC-2) is used for the numerical field computations. It is found that when lightning strikes the elevated object which is nearby to the building, induces more currents in steel parts of the building rather than the current due to nearby strike to ground. The height of the elevated object also has significant effect on the magnitude of the induced current.
\end{abstract}

Keywords: lightning, induced currents, steel reinforced columns and beams, concrete buildings and Elevated striking object

Cite This Article: Vishwanath Hegde, and Vinoda shivanand, "A Comparative Study on Induced Currents in Steel Reinforced Building Due to a Nearby Lightning Strike to Ground and a Strike to Nearby Elevated Object.” American Journal of Electrical and Electronic Engineering 2, no. 1 (2014): 1-5. doi: 10.12691/ajeee-2-1-1.

\section{Introduction}

Lightning flashes involve currents having high magnitude and high rate of rise. When lightning strikes directly to the tall structures on the earth, such as transmission line towers, telecommunication towers, wind turbines, buildings etc., large amount of current flows in them. From the literature it is found that, when lightning strikes to a building, it generates transient electromagnetic fields and surges on the power and communication circuits inside the building. These fields and surges can cause the malfunction or damage to the sensitive equipments installed in the buildings [1]. Also, however when lightning strikes the ground in the vicinity of the structures, large amount of currents are induced in such structures. The magnitude and nature of such induced currents depend upon various parameters of lightning current such as rate of rise of current, velocity of propagation, channel inclination, distance between structure and striking point etc. and also on physical parameters of the structures [2,3]. It is found from the study that, presence of nearby conducting objects in between down conductor (structure) and strike is found to have effect on the induced currents [4]. There is a large amount of literature on the problem of induced currents due to lightning [5-13]. However, to the best of the author's knowledge, a comparative study on induced currents in steel of a steel reinforced building due to nearby lightning stroke and stroke to elevated object seems to be limited. Therefore in this work a study is carried out to determine the magnitude and nature of induced currents in different steel parts of the building due to a nearby lightning stroke and stroke to nearby elevated object. A comparison of the results is also presented.

\section{Present Work}

In this paper, work is carried out to determine the magnitude and nature of the induced currents in different steel parts of the building due to nearby stroke to ground and stroke to nearby elevated object.

For the intended study, different heights of building and different heights of elevated objects at different distances from the building are considered. The rods of columns and beams of the building, lightning channel and elevated objects are modeled as vertical conductors. Such models have been successfully employed in the literature pertaining to the evaluation of the induced current and field due to a strike on an elevated object $[14,15,16,17]$. Tall down conductors are known to initiate significant upward leader activities, such upward connecting leader activity from the conductors is not taken into account. For 
numerical analysis, the conductor is divided into cylindrical segments. The computation is carried out in the frequency range from $50 \mathrm{kHz}$ to $3 \mathrm{MHz}$ with the increment step of $5.0 \mathrm{kHz}$. Following the earlier works, a perfectly conducting ground is assumed and to realize the soil resistance, a footing resistance of $6 \Omega$ is connected at the base of the pillars of building and ground and at the base of elevated object and ground [4]. Simulations are carried out with the stroke to ground and stroke to elevated objects at different distances such as $30 \mathrm{~m}$ and 60 $\mathrm{m}$ from the building. Different rise time and velocity of propagation of the channel current are considered.

\subsection{Theoretical Modeling}

As the electromagnetic field produced by the lightning is basically responsible for the current induction, the model to be employed for the study must be based on an electromagnetic model. Such a model, which is also called the antenna theory (AT) model, has been quite successfully employed in the literature for the estimation of currents and the field in the vicinity $[8,9,10,11]$. Based on this and the earlier work, in the present work also, an electromagnetic model is employed. In the electromagnetic modeling approach, the channel is considered as a thin wire antenna supporting a transverse magnetic (TM) mode. The channel excitation is represented by a lumped current source, which is a highly simplified representation for the actual excitation formed by the distributed charges along the channel. Further, even though the actual bridging point for Elevated Strike Object (ESO) can be quite elevated, possibly due to the dominating channel equivalent impedance, placement of lumped source at the top of ESO yields reasonably satisfactory results [10]. In view of the same, lumped current source placed at the channel base is employed for the required excitation. The phenomena of induction to the down conductor can be treated as linear. In view of this, the stroke current is normalized to unit amplitude. In the simulations, the stroke current is expressed as a double exponential function of the form

$$
I=I_{0}\left(e^{-a t}-e^{-b t}\right)
$$

$I_{0}$ is the factor that depends upon peak value of current, a and $b$ controls the front and tail times of the current wave in $\mu \mathrm{s}$.

Similar to the commonly employed channel base current waveform for the simulation of lightning return stroke fields [18]; this waveform has the maximum $d i / d t$ region near the origin. Therefore, the influence of tail portion is segregated from that of the region in front, which produces maximum induction. The lightning channel is assumed to be vertical, and a double exponential current of unit amplitude and a time to peak of $1.2 \mu \mathrm{s}$ and $3.7 \mu \mathrm{s}$ is chosen $[2,3,4,5,6]$. The associated rise time between $10 \%$ and $90 \%$ is $0.565 \mu$ s and $2.4 \mu$ s. The corresponding parameters of the exponential function are $a=3.08 \times 10^{6}, b=6.25 \times 10^{4}$, and $I_{0}=1.1365$. Simulations are carried out with the stroke to ground at different distances such as $30 \mathrm{~m}$ and $60 \mathrm{~m}$ from the building. The numbering of the columns and rods of the columns are shown in Figure 1.

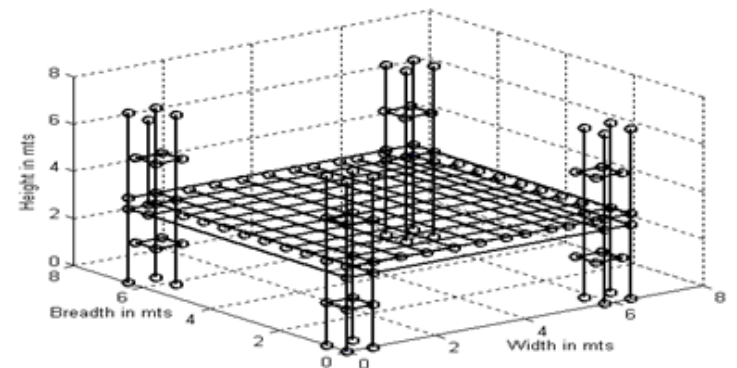

(a)

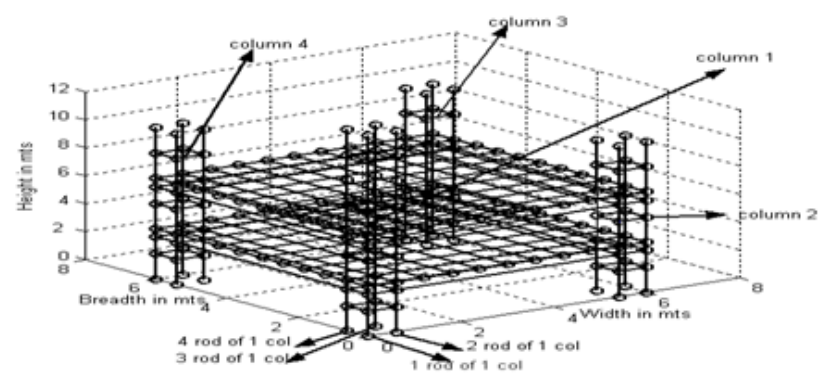

(b)

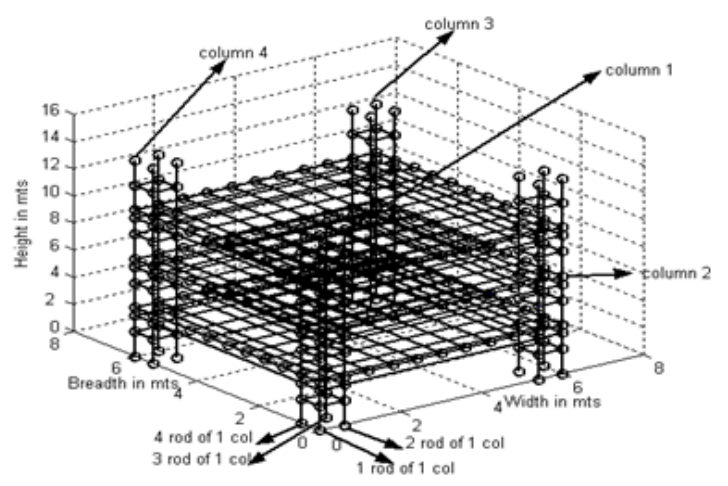

(c)

Figure 1. Steel structure of building model

\subsubsection{Modeling of the Channel}

The lightning channel is modeled as a vertical conducting cylinder of radius $2.5 \mathrm{~mm}$, with a current source at the channel base. The channel lengths selected for the study is $1 \mathrm{~km}$. The channel is considered as thin wire model.

\subsubsection{Modeling of the Source}

A current source model for the source is considered. In order to realize the same in the simplified numerical model, a voltage source with a high series resistance (of about $5 \mathrm{k} \Omega$ ) is employed at the junction between the channel and the conductor. 


\subsubsection{Modeling of the Steel Structure of Building and Elevated Object}

The steel structure of building of three different heights is considered. Building with only ground floor has dimensions $6.4 \mathrm{~m} \mathrm{X} 6.4 \mathrm{~m} \mathrm{X} 3.6 \mathrm{~m}$ with pillars extended to a height of $7.2 \mathrm{~m}$, building with ground and first floor has dimensions $6.4 \mathrm{~m} \mathrm{X} 6.4 \mathrm{~m} \mathrm{X} \mathrm{2(3.6)} \mathrm{m} \mathrm{with} \mathrm{pillars}$ extended to a height of $10.8 \mathrm{~m}$, and building with ground, first and second floor has dimensions $6.4 \mathrm{~m} \mathrm{X} 6.4 \mathrm{~m} \mathrm{X}$ 3(3.6) $\mathrm{m}$ with pillars extended to a height of $14.4 \mathrm{~m}$ is considered. Each column and beam consists of four steel rods of $20 \mathrm{~mm}$ diameter. Each rod of columns and beams of building are modeled as a cylindrical conductor with appropriate ground termination resistance. Elevated striking object is considered as vertical conductor of different heights and is modeled as vertical cylindrical conductor of $20 \mathrm{~mm}$ diameter. The steel structure of the building model considered for the study is shown in Figure 1.

\subsubsection{Parameters for the Study}

In the present work, the different parameters of the lightning current such as rate of rise of current, velocity of propagation, height of the building, height of elevated object and distance between building and stroke or elevated striking object are considered. Sample simulation results are presented here.

\section{Simulation Results and Analysis}

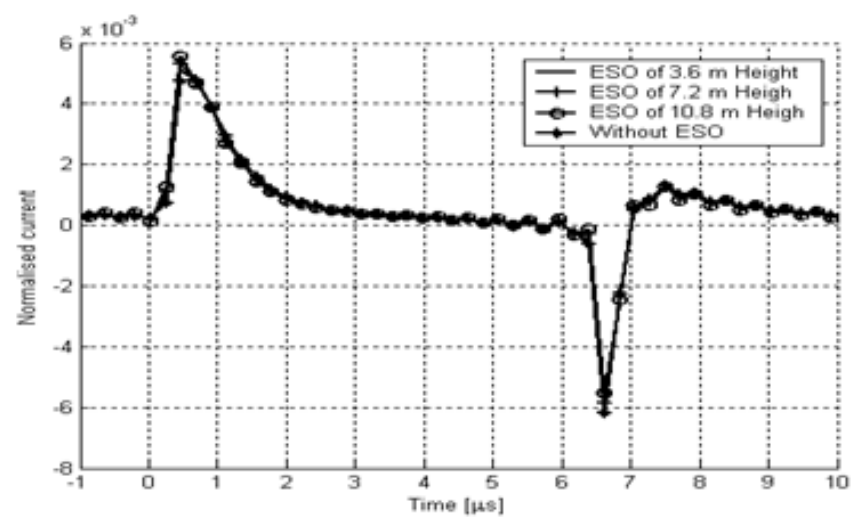

(a)

\subsection{Simulation Results Corresponding to Building Model}

\section{(a) Stroke at a distance of $30 \mathrm{~m}$ and $60 \mathrm{~m}$ from the building}

Simulations are carried out for building model shown in Figure 1 (a) having only ground floor in it for two gaps distance between building and channel. Figure 2 shows plot of induced current at the base of 1 column for a stroke to ground and stroke to elevated object of different heights at a distance of $60 \mathrm{~m}$ and $30 \mathrm{~m}$ from the building. The normalized peak value of the currents at the base of all the four columns for different heights of the elevated object at a distance of $30 \mathrm{~m}$ from the building is tabulated in Table 1. From the results it is observed that the magnitude of the induced current is more in all the four columns compared to the currents due to a strike to ground. This increase in current is about $1.9 \%, 7.6 \%, 6.9 \%$ and $1.5 \%$ in column 1 , 2, 3 and 4 respectively when an elevated strike object of height $3.6 \mathrm{~m}$ is present at a distance of $30 \mathrm{~m}$ from the building. It is clear that as the $2^{\text {nd }}$ column is more close to elevated strike object than the other three columns maximum increase in current is found in it. As the $4^{\text {th }}$ column is far away compared to other three columns minimum increase in current is found in it. It is also observed that the amount of increase in current is increasing with the height of the elevated strike object. For elevated object of height $10.8 \mathrm{~m}$ the increase in current is in the rang of $7.8 \%$ to $13.6 \%$

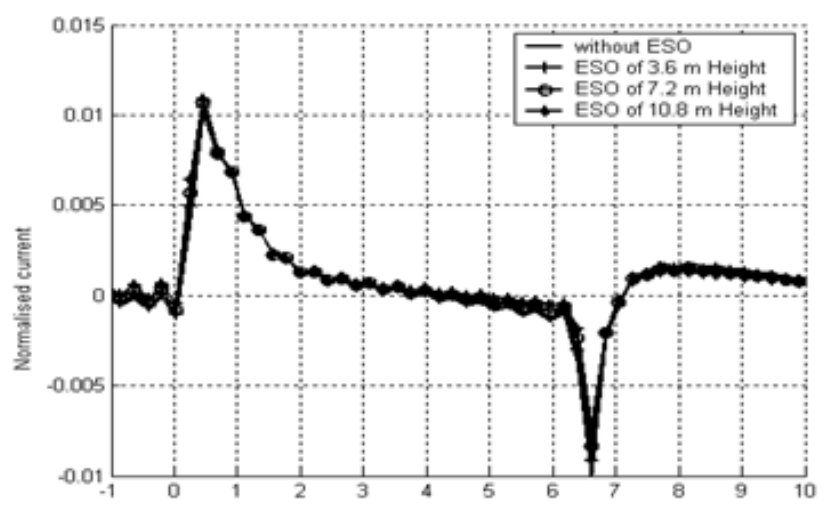

(b)

Figure 2. Current at the base of $1^{\text {st }}$ column for a strike to ground and strike to elevated object at a distance $60 \mathrm{~m}$ and $30 \mathrm{~m}$ from the building

Table 1. Peak value of current in $\mathrm{mA}$ at the base of all the four columns for different heights of elevated object at a distance $30 \mathrm{~m}$ and $60 \mathrm{~m}$ from the building

\begin{tabular}{|c|c|c|c|c|c|c|c|c|}
\hline \multirow{2}{*}{$\frac{\text { Height of elevated object }}{\text { Gap distance }}$} & \multicolumn{2}{|c|}{$3.6 \mathrm{~m}$} & \multicolumn{2}{|c|}{$7.2 \mathrm{~m}$} & \multicolumn{2}{|c|}{$10.8 \mathrm{~m}$} & \multicolumn{2}{|c|}{0 m (stroke to ground) } \\
\hline & $30 \mathrm{~m}$ & $60 \mathrm{~m}$ & $30 \mathrm{~m}$ & $60 \mathrm{~m}$ & $30 \mathrm{~m}$ & $60 \mathrm{~m}$ & $30 \mathrm{~m}$ & $60 \mathrm{~m}$ \\
\hline Column 1 & 10.40 & 5.14 & 10.07 & 5.34 & 11.00 & 5.58 & 10.20 & 4.78 \\
\hline Column 2 & 12.60 & 5.73 & 13.00 & 6.00 & 13.30 & 6.20 & 11.70 & 5.50 \\
\hline Column 3 & 14.50 & 7.60 & 14.50 & 7.60 & 15.00 & 7.66 & 10.60 & 6.70 \\
\hline Column 4 & 11.00 & 6.80 & 11.50 & 6.82 & 11.80 & 6.90 & 13.80 & 6.70 \\
\hline
\end{tabular}

(b) For two different velocities of propagation of channel current

It is well known that the velocity of propagation has the influence on induced currents [3]. Therefore simulations are carried out for fast and slow velocity of propagation of current. The simulation results are presented here for the building model shown in fig. 1 (b) which has ground and first floor in it. Figure 3 shows plot of induced current at the base of $1^{\text {st }}$ column for a stroke to ground and stroke to elevated object of different heights at a distance of $60 \mathrm{~m}$ from the building for velocity of propagation of channel current, equal to $\mathrm{c} / 3$ and $\mathrm{c}$, where $\mathrm{c}$ is velocity of light. 
The normalized peak value of the current at the base of all

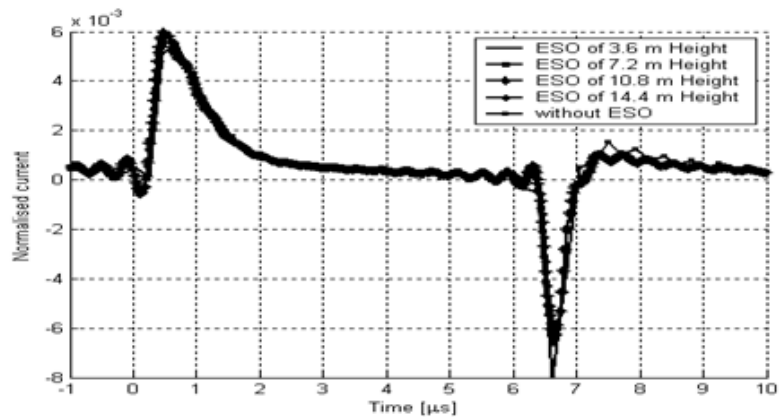

(a) the four columns is tabulated in Table 2.

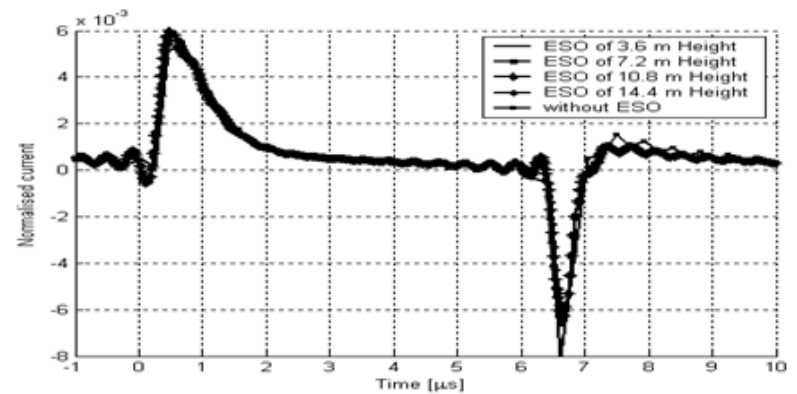

(b)

Figure 3. Current at the base of $1^{\text {st }}$ column for a strike to ground and strike to elevated object at a distance $30 \mathrm{~m}$ from the building (a) For velocity of propagation of lightning current equal c/3(velocity of light) (b) For velocity of propagation of lightning current equal to c

From the results it is clear that the magnitude of current induced in this building having pillar height $10.8 \mathrm{~m}$ is more than that in the building having pillar of height 7.2 $\mathrm{m}$ for the strike at a distance of $60 \mathrm{~m}$. The elevated object of height $3.6 \mathrm{~m}$ and $7.2 \mathrm{~m}$ are small in height compared to height of the pillars. Therefore the effect on induced current is less. However the elevated objects of height
$10.8 \mathrm{~m}$ and $14.4 \mathrm{~m}$ which are equal to and more than height of the pillars respectively have an influence to induce more current than the strike to ground. For full velocity of propagation the increase in current is from $13 \%$ to $15 \%$ for elevated object of height $14.4 \mathrm{~m}$ and it is from $23 \%$ to $30 \%$ for slow velocity of propagation.

Table 2. Peak value of current at the base of all the four columns in $\mathrm{mA}$ for different heights of elevated object at a distance $60 \mathrm{~m}$ from the building for propagation velocity equal to $\mathrm{c}$ and $\mathrm{c} / 3$

\begin{tabular}{|c|c|c|c|c|c|c|c|c|c|c|}
\hline \multirow{2}{*}{$\begin{array}{c}\text { Height of elevated object } \\
\text { Velocity of propagation }\end{array}$} & \multicolumn{2}{|c|}{$3.6 \mathrm{~m}$} & \multicolumn{2}{|c|}{$7.2 \mathrm{~m}$} & \multicolumn{2}{|c|}{$10.8 \mathrm{~m}$} & \multicolumn{2}{|c|}{$14.4 \mathrm{~m}$} & \multicolumn{2}{|c|}{$0 \mathrm{~m}$ (stroke to ground) } \\
\hline & c & c/3 & c & c/3 & c & $\mathbf{c} / 3$ & c & c/3 & c & c/3 \\
\hline Column 1 & 5.40 & 5.30 & 5.71 & 5.70 & 6.00 & 6.00 & 6.40 & 6.20 & 5.30 & 4.70 \\
\hline Column 2 & 6.12 & 6.46 & 6.50 & 6.50 & 6.74 & 6.72 & 7.10 & 6.90 & 6.06 & 5.30 \\
\hline Column 3 & 9.20 & 8.30 & 9.22 & 8.90 & 8.90 & 9.00 & 9.20 & 9.20 & 9.22 & 8.24 \\
\hline Column 4 & 8.01 & 8.00 & 8.35 & 8.12 & 8.35 & 8.26 & 8.35 & 8.35 & 8.00 & 7.60 \\
\hline
\end{tabular}

\section{(c) For two different rise time of channel current}

It is known that magnitude of induction is clearly dependent on the rate of rise of the stroke current [3]. Therefore here simulations are carried out for two time to peak values $1.2 \mu \mathrm{s}$ and $3.7 \mu \mathrm{s}$. The simulation results

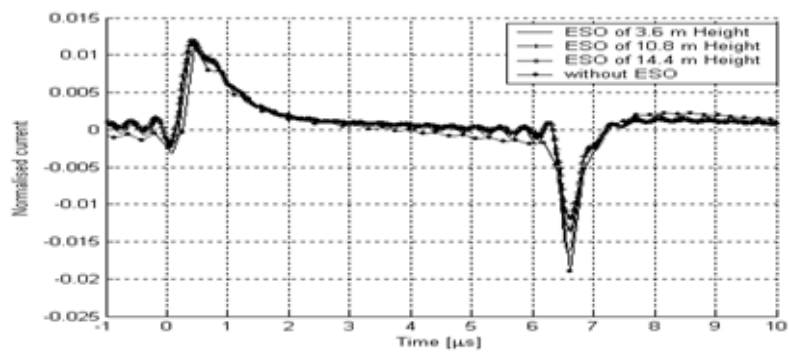

(a) corresponding to building model shown in Fig.1 (c) are presented here. Simulation results for strike to ground and strike to elevated objects at a distance $30 \mathrm{~m}$ from the building are shown in Figure 4. The peak value of currents are tabulated in Table 3.

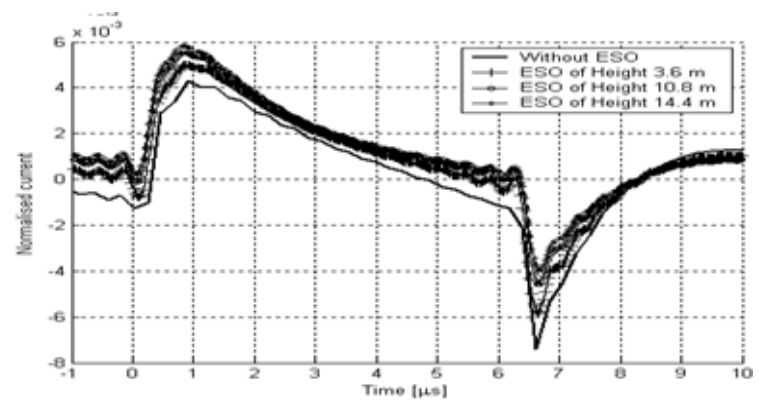

(b)

Figure 4. Current at the base of $1^{\text {st }}$ column for a strike to ground and strike to elevated object at a distance $30 \mathrm{~m}$ from the building (a) For time to peak equal to $1.2 \mu \mathrm{s}$ (b) For time to peak equal to $3.7 \mu \mathrm{s}$

Table 3. Peak value of current at the base of all the four columns for different heights of elevated object at a distance $60 \mathrm{~m}$ from the building for propagation velocity equal to velocity of light for time to peak $1.2 \mu \mathrm{s}$ and $3.7 \mu \mathrm{s}$

\begin{tabular}{|c|c|c|c|c|c|c|c|c|}
\hline \multirow{2}{*}{$\begin{array}{l}\text { Height of elevated object } \\
\text { Time to peak value in } \mu \mathrm{s}\end{array}$} & \multicolumn{2}{|c|}{$3.6 \mathrm{~m}$} & \multicolumn{2}{|c|}{$10.8 \mathrm{~m}$} & \multicolumn{2}{|c|}{$14.4 \mathrm{~m}$} & \multicolumn{2}{|c|}{0 m (stroke to ground) } \\
\hline & 1.2 & 3.7 & 1.2 & 3.7 & 1.2 & 3.7 & 1.2 & 3.7 \\
\hline Column 1 & 11.00 & 5.00 & 11.60 & 5.50 & 12.00 & 5.80 & 11.00 & 5.00 \\
\hline Column 2 & 13.50 & 6.30 & 14.30 & 6.92 & 14.70 & 7.20 & 13.40 & 6.30 \\
\hline Column 3 & 21.50 & 9.26 & 21.40 & 10.00 & 21.50 & 10.00 & 21.00 & 9.26 \\
\hline Column 4 & 17.30 & 7.70 & 17.50 & 7.90 & 17.50 & 7.90 & 17.00 & 7.70 \\
\hline
\end{tabular}


It is observed that with slow impulse, magnitude of current induced is very less compared to the current with fast impulse. The elevated object of height $3.6 \mathrm{~m}$ and 7.2 $\mathrm{m}$ has negligible influence to increase the current as compared to strike to ground .The elevated object of height $14.4 \mathrm{~m}$ has an influence to increase the current by $2 \%$ in $4^{\text {th }}$ pillar and about $10 \%$ in $2^{\text {nd }}$ pillar for fast impulse.

\section{Conclusion}

From the simulation results it is concluded that strike to nearby elevated objects induces more current in the building compared to that induced due to nearby strike to ground. When striking object height is very less compared to height of the pillars, the influence of the current is less. However, when height of the elevated object is comparable more influence is found on the induced current. Strike to elevated object is found to have similar effect for increased distance between building and elevated object or channel, reduced velocity of propagation and for impulse having low time to peak.

\section{Acknowledgement}

The authors would like to acknowledge valuable suggestions made by the referees in improving the presentation of this paper.

\section{References}

[1] Y. Du and M. L. Chen "Influence of building structures on the lightning return stroke current", IEEE trans. power delivary,vol.25, no 1,January 2010.

[2] U. Kumar, V. Hegde, and V. Shivanand, "Preliminary studies on the characteristics of the induced current in simple down conductors due to a nearby lightning strike”, IEEE Trans.EMC, vol.48, no.4, pp.805-816, 2006

[3] V.Hegde, V.Shivanand " On the Characteristics of Lightning currents in the Steel reinforced Concrete Building due to a Lightning Strike”, Proceedings of APEMC, May 23-25, 2012, Singapore.
[4] V.Shivanand, V.Hegde and U.Kumar,“ On the Influence of Neighboring Conducting Objects on the Induced Currents in Simple Down Conductors Due to Nearby Lightning Strike", Electric power components and Systems, October 2012.

[5] V.Hegde, U.Kumar "Studies on characteristics of lightning Generated currents in an interconnected lightning protection system", Journal of Electrostatics 67 (2009) pages 590- 596.

[6] V.Hegde, G.R..Konkolienker and Udaya Kumar, "Numerical Electromagnetic analysis of current and voltage distribution along down Conductors and towers hit by direct Lightning”, Electric power components and Systems, Feb 2011.

[7] J.KATO, H.KAWANO, T. Tominaga, S. KURAMOT "Investigation on lightning surge current induced in reinforced concrete buildings by direct strikes", IEEE trans, EMC, vol. 3,2001 .

[8] M. Bandinelli, F. Bessi, S. Chiti, M. Infantino and R. Pomponi, "Numerical modelling for LEMP effect evaluation inside a Telecommunication exchange", IEEE trans EMC, vol .38,No.3, August 1996-1998, pp.265-273.

[9] V.A. Rakov, M.A.Uman, M.I.Fernandez, "Direct lightning strikes to The lightning protective system of a residential building: triggered - lightning experiment", IEEE trans on power delivery, vol. 17, No.2, April 2002,pp 575-586.

[10] Y. Baba and M. Ishi, "Numerical electromagnetic field analysis of lightning current in tall structures," IEEE Trans. power delivery. vol. 16, no. 2,pp. 324-328, Apr. 2001.

[11] Mosaddeghi, Shoory, Rachidi,Rubinstein, Diendor,Pichler and pavenello " Lightning return stroke to tall towers : Ability of Engineering and Electromagnetic fields" IEEE trans EMC, vol. 54, No.4, 2012, pp.889-897.

[12] Bo Yang ,Bi - Hua Zhou, Bin Chen, Jiao - Bao Wang, and Xin Meng "Numerical study of Lightning induced currents on Buried cables and Shield wire protection method" IEEE trans EMC, vol .54,No.2,2012, pp.323-331.

[13] B. Kordi, R. Moini, W. Janischewskyj, A. M. Hussein, V. O. Shostak,and V. A. Rakov, "Application of the antenna theory model to a tall tower struck by lightning,” J. Geophys. Res., vol. 108, no. D17, 4542, pp. ACL7/1-ACL7/9, 2003.

[14] Y. Baba and M. Ishi, "Characteristics of electromagnetic returnstroke models,” IEEE Trans.EMC., vol. 45, no. 1, pp. 129-134, Feb. 2003.

[15] C. A. Nucci, G. Diendorfer, M. A. Uman, F. Rachidi, M. Ianoz, and C Mazzetti, "Lightning return stroke current models with specified channel-base current: A review and comparison," J. Geophys. Res., vol. 95, no. D12, pp. 20 395-20 408, Nov. 1990.

[16] V. A. Rakov, "Transient response of a tall object to lightning," IEEE Trans. EMC, vol 43, no. 4, pp. 654-661, Nov.2001.

[17] Y. Baba and V. A. Rakov, "Lightning electromagnetic environment in the presence of a tall grounded strike object," J. Geophys. Res., vol. 110, pp. D09108/1 D09108/18, May 2005.

[18] G. J. Burke and A. J. Poggio, "Numerical electromagnetic code (NEC)-method of moments Part I \& III," Naval Ocean Syst. Center, San Diego, CA, Tech. Rep. 116, 1980. 